\title{
ESTUDO DA PRODUÇÃO DE BIOQUEROSENE VIA CRAQUEAMENTO TÉRMICO CATALÍTICO DE MATERIAL LIPÍDICO DE CAIXAS DE GORDURA DO RU-UFPA
}

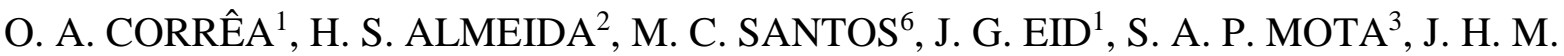 \\ SANTOS $^{5}$, M. L. SANTOS ${ }^{5}$, N. T. MACHADO ${ }^{4}$ \\ ${ }^{1}$ Universidade Federal do Pará, Programa de Pós-Graduação em Engenharia Química \\ ${ }^{2}$ Universidade Federal do Pará, Faculdade de Engenharia Ambiental e Sanitária \\ ${ }^{3}$ Universidade Federal do Sul e Sudeste do Pará, Faculdade de Engenharia de Materiais \\ ${ }^{4}$ Universidade Federal do Pará, Faculdade de Engenharia Química \\ ${ }^{5}$ Universidade Federal do Pará, Graduandos em Engenharia Química \\ ${ }^{6}$ Universidade Federal do Pará, Programa de Doutorado em Engenharia de Recursos Naturais da \\ Amazônia \\ E-mail para contato: acneto08@gmail.com
}

\begin{abstract}
RESUMO - Neste trabalho foi investigado o processo de produção de Biocombustíveis via Craqueamento Térmo-Catalítico do Material Lipídico das Caixas de Gordura do RUUFPA. O Material Residual das Caixas de Gordura após coletado foi submetido a uma série de Operações de Separação Físicas (Peneiramento, Decantação, e Desidratação) em uma Unidade Piloto de Desodorização, objetivando a remoção dos sólidos em suspenção, a formação do sistema bifásico Gordura Residual - Fase Aquosa, a remoção da Fase Aquosa, e a desidratação parcial e homogeneização da Gordura Residual. Em seguida, a Gordura Residual foi processada na Unidade Piloto de Craqueamento a $450^{\circ} \mathrm{C}, 150 \mathrm{rpm}$, e $10 \%(\mathrm{~m} / \mathrm{m})$ de $\mathrm{Na}_{2} \mathrm{CO}_{3}$ como catalisador. A Fase Aquosa foi submetida às analises físico-químicas e bacteriológicas conforme os Métodos Oficiais da APHA, enquanto a Gordura Residual foi analisada de acordo com os Métodos Oficiais AOCS e ASTM. O Produto Líquido Orgânico (PLO), condensado obtido na reação com I.A = 14.97 $\mathrm{mgKOH} / \mathrm{gPLO}$ e rendimento em Basa Seca de $68.72 \%$, foi fracionado em uma Unidade Piloto de Destilação, objetivando obter Frações de Biocombustíveis semelhantes ao Querosene, sendo o rendimento da Fração de Querosene de 15.07 \%. O PLO e a Fração Destilada de Biocombustível (Querosene Verde) foram analisados de acordo com os Métodos Oficiais AOCS e ASTM.
\end{abstract}

\section{INTRODUÇÃO}

Os óleos e gorduras usados no processo de fritura de alimentos geram uma quantidade considerável de resíduos (BARROS et al., 2008). Em estabelecimentos comerciais (restaurantes, lanchonetes, etc.), agroindustriais, assim como residências, os óleos e as gorduras residuais das frituras são coletados em Caixas de Gorduras, sendo, em geral, dispostos em Aterros Sanitários, gerando volumes significativos de resíduos. Neste sentido, a utilização destes resíduos, ricos em 
material lipídico e de baixo custo vem sendo investigados como matéria prima na produção de biocombustíveis (RATTON, 2012), possibilitando a produção de biocombustíveis a partir de resíduos lipídicos de Caixas de Gorduras, assim como a redução da quantidade e o volume de dejetos depositados em Aterros Sanitários (MARCHETTI et al., 2005).

Em geral, a rota tecnológica comumente utilizada na produção Biocombustível a partir de materiais lipídico é a transesterificação homogênea alcalina. Embora, este processo possua inúmeras vantagens, o mesmo exige que a matéria-prima seja isenta de água e baixíssima acidez (MEHER et $a l ., 2006)$, de forma que, matérias primas lipídicas residuais necessitam serem submetidas a Etapas de Filtração, Extração Líquido-Líquido, Branqueamento e Desacidificação, o que compromete a economicidade do processo (SANTOS et al., 2010). Neste contexto, o processo de craqueamento termo catalítico de materiais residuais (RATTON, 2012, MOTA, 2013), o qual produz mistura de hidrocarbonetos e compostos oxigenados com propriedades semelhantes às do diesel de petróleo (KNOTHE et al., 2009), se torna uma alternativa atrativa a transesterificação homogênea alcalina.

Neste trabalho foi investigado a viabilidade da produção de frações de biocombustíveis semelhantes ao Querosene Verde via craqueamento térmico catalítico da gordura residual, coletadas das Caixas de Gordura do Restaurante Universitário da UFPA, utilizando-se $10 \%$ (m/m) de $\mathrm{Na}_{2} \mathrm{CO}_{3}$ como catalisador, seguida de destilação do Produto Líquido Orgânico (PLO) em uma Unidade Piloto de Destilação.

\section{MATERIAIS E MÉTODOS}

\subsection{Materiais}

A Gordura Residual foi coletada manualmente das Caixas de Gordura do Restaurante Universitário da UFPA utilizando-se Baldes Plásticos de 20 litros (Figura 1). Após a Coleta, o Material Residual contendo a Gordura Residual, Fase Aquosa, e Sólidos em Suspensão, foi acondicionado em Tambores Plásticos de 70 litros. O catalisador Carbonato de Sódio $\left(\mathrm{Na}_{2} \mathrm{CO}_{3}\right)$, Soda Comercial ASH Leve (D50), com pureza de $98.0 \%(\mathrm{~m} / \mathrm{m})$ foi adquirido da Solvay Chemicals International SA (Brussels, Belgium).

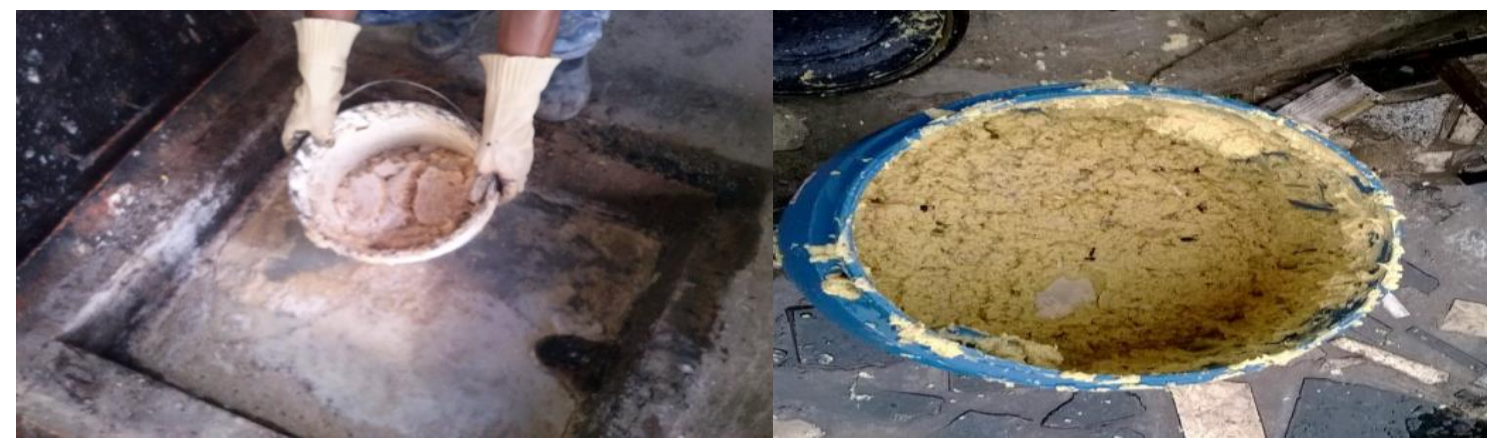

Figura 1 - Coleta do Material Residual das Caixas de Gordura do RU-UFPA. 


\section{9 a 22 de outubro de 2014 \\ Florianópolis/SC}

\subsection{Pré-processamento do Material Residual}

Peneiramento e classificação: O Material Residual foi transferido para Recipientes Plásticos de 20 litros objetivando dissolver a Gordura Residual, utilizando-se 01 (um) EBULIDOR ALUMÍNIO (IMC, Modelo: 1000 Watts/127 Volts), por um período de 20 (vinte) minutos, atingindo aproximadamente $80^{\circ} \mathrm{C}$. Em seguida, o Material Residual foi pesado em Balança Industrial Mecânica (MICHELETTI, Modelo: MIC 2/B, 2-300 Kg, e = $0.1 \mathrm{~kg}$ ) e transferido para 01 (um) Tanque de PEAD (Polietileno de Alta Densidade), de geometria cilíndrica de $520 \mathrm{~L}$, no qual foi acoplado na parte superior um Sistema de Peneiramento de geometria cilíndrica com $560 \mathrm{~mm}$ de diâmetro e 480 mm de altura, construído de peneiras metálicas de 3 1⁄2 MESH na área lateral e peneiras metálicas de 6 MESH na área da base, conforme ilustrado na Figura 2. Este Sistema de Peneiras \& Classificação permitiu a remoção de resíduos sólidos grossos (Legumes, Verduras, Grãos de Arroz e Feijão, Palitos, Papel, Plásticos, etc.), e a formação do sistema monofásico homogêneo Gordura Residual Solúvel (Gordura + Fase Aquosa) no Tanque de PEAD.

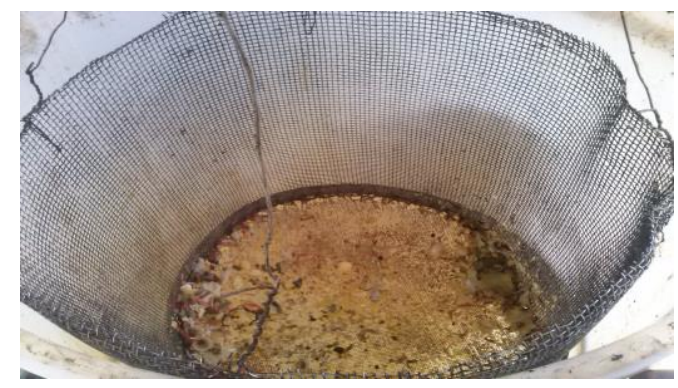

Figura 2 - Sistema de Peneiramento e Classificação.

Decantação: No Processo de Decantação, o sistema monofásico homogêneo Gordura Residual Solúvel foi transferido por vácuo ( 300 mbar), do Tanque de PEAD para a Unidade Piloto de Desodorização/Desidratação de $750 \mathrm{~L}$, de geometria cilíndrica ovalar, ilustrada na Figura 3. Em seguida, deixou-se em repouso, por um período de 30 (trinta) minutos, o sistema monofásico homogêneo Gordura Residual Solúvel, objetivando-se a formação do sistema bifásico Gordura Residual - Fase Aquosa, possibilitando por diferença de densidade, a remoção da Fase Aquosa, através da abertura da válvula de fundo do Reator de Desodorização/Desidratação, a qual foi pesada na Balança Industrial Mecânica descrita em peneiramento e classificação, sendo parte deste material coletado em Recipientes Plásticos de 5 L, e acondicionado para posteriores análises físico-químicasbacteriológicas no Laboratório de Controle da Qualidade da Água do LAESA-UFPA.

Homogeneização da gordura residual: Após a remoção da Fase Aquosa do sistema bifásico Gordura Residual - Fase Aquosa, através da abertura da válvula de fundo do Reator de Desodorização/Desidratação, a Gordura Residual no Estado Semi-Sólido, devido à diminuição de temperatura (Equilíbrio Térmico), foi novamente aquecida até aproximadamente $80^{\circ} \mathrm{C}$ sob vácuo $(\sim$ 300 mbar), e agitação a $80 \mathrm{rpm}$, por um período de 02 (duas) horas, visando a desidratação parcial, assim como a homogeneização da Gordura Residual. Em seguida, a Gordura Residual Líquida $($ Gordura + Água) foi removida, através da abertura da válvula de fundo do Reator de 


\section{9 a 22 de outubro de 2014 \\ Florianópolis/SC}

Desodorização/Desidratação, sendo pesada na Balança Industrial Mecânica.

\subsection{Craqueamento Térmico Catalítico da Gordura Residual}

Após o Processo de Homogeneização, a Gordura Residual Líquida aferida foi transferida para o Tanque de Alimentação de PEAD (V-01), de geometria cilíndrica e capacidade de 200 L, da Unidade Piloto de Craqueamento Termo-Catalítico do LEQ-UFPA, objetivando-se produzir o Produto Líquido Orgânico (PLO), utilizando-se aproximadamente $10 \%$ de Carbonato de Sódio $\left(\mathrm{Na}_{2} \mathrm{CO}_{3}\right)$ como catalisador (3.0 kg de $\mathrm{Na}_{2} \mathrm{CO}_{3}$ ). Em seguida, a Gordura Residual Líquida foi bombeada através de 01 (um) Trocador de Calor (Sistema de Pré-Aquecimento), construído em Aço Inox, contendo um sistema de resistências elétricas de potência $15 \mathrm{~kW}$, atingindo na saída do Sistema de PréAquecimento aproximadamente $200{ }^{\circ} \mathrm{C}$, sendo a corrente material direcionada para o Reator de Craqueamento, construído de Aço Inox, com geometria cilíndrica, capacidade de 150 L (R-01), e Unidade de Controle do Sistema de Agitação e Sistema de Combustão, assim como os Displays de Temperatura do Reator, Condensador, Exaustão, Selagem Mecânica e Vaso de Coleta. Ao atingir 120 ${ }^{\circ} \mathrm{C}$, a Água Remanescente na Gordura Residual Líquida (Gordura + Água) foi evaporada e coletada no Tanque de Condensado (V-02), sendo pesada na Balança Industrial Mecânica. O Craqueamento Termo-Catalítico da Gordura Residual foi realizado a $450{ }^{\circ} \mathrm{C}$, tendo sido mantida a Temperatura do Reator (R-01), após atingir $450{ }^{\circ} \mathrm{C}$, por um período de 60 (sessenta) minutos.

\subsection{Destilação Fracionada do Produto Líquido Orgânico}

O Produto Líquido Orgânico do Processo de Craqueamento Térmico Catalítico da Gordura Residual, utilizando-se aproximadamente $10 \%$ de Carbonato de Sódio $\left(\mathrm{Na}_{2} \mathrm{CO}_{3}\right)$ como catalisador (3.0 kg de $\mathrm{Na}_{2} \mathrm{CO}_{3}$ ), a $450{ }^{\circ} \mathrm{C}$ foi destilado na Unidade Piloto de Destilação do LEQ-FEQ (Figura 3C), com capacidade de $50 \mathrm{~L}, 1.5 \mathrm{~m}$ de enchimento randômico de Anéis de Rashing de Vidro, vaso coletor de condensado $5 \mathrm{~L}$, condensador tubular espiral de $0.2 \mathrm{~m}^{2}$ de área de troca térmica, e controle digital de temperatura e taxa de aquecimento. Foram introduzidos $8.36 \mathrm{~kg}$ de PLO na Coluna de Destilação, sendo a temperatura máxima fixada em $235^{\circ} \mathrm{C}$, de forma a abranger as faixas de temperatura das frações de gasolina $\left(40^{\circ} \mathrm{C}<\mathrm{T}<175^{\circ} \mathrm{C}\right)$ e querosene $\left(175^{\circ} \mathrm{C}<\mathrm{T}<2135^{\circ} \mathrm{C}\right)$.

\subsection{Análises Físico-químicas e Bacteriológicas}

Análises físico-químicas e bacteriológicas da fase aquosa: A Fase Aquosa do sistema bifásico Gordura Residual - Fase Aquosa, removida através da abertura da válvula de fundo do Reator de Desodorização/Desidratação, foi submetida às análises físico-químicas e bacteriológicas no Laboratório de Controle da Qualidade da Água do LAESA-UFPA, em termos de pH, DBO, DQO, NAmoniacal, Sólidos em Suspensão (SS), Sólidos em Suspensão Totais (SST), Sólidos em Suspensão Fixos (SSF), ), Sólidos em Suspensão Voláteis (SSV), Sólidos Totais (ST), Sólidos Totais Fixos (STF), Sólidos Totais Voláteis (STV), Alcalinidade Total (AT), Ácidos Graxos Voláteis (AGV), Sulfato, Fósforo, Coliformes Totais, e Coliformes Termotolerantes, conforme os Métodos Oficiais da APHA.

Análises físico-químicas da gordura residual: A Gordura Residual do sistema bifásico Gordura 
Residual - Fase Aquosa, removida após homogeneização via aquecimento e agitação, foi analisada em termos do Índice de Acidez. AOCS Cd 3d-63, Índice de Saponificação AOCS Cd 3-25, Densidade pelo método do Picnômetro ASTM D854 at $25^{\circ} \mathrm{C}$, Viscosidade Cinemática ASTM 446 e ASTM D 2515 usando o Viscosímetro Cannon-Fenske (Schot Geräte, Modelo: 520 23), com tubo capilar No. 200, Corrosividade ao Cobre método ABNT/NBR 14359, usando o equipamento (PETROTEST DP, Modelo: E 25-0600).

Análises físico-químicas do PLO e bioquerosene: O PLO e a fração de Biocombustível (Bioquerosene) obtida via Destilação na faixa de temperatura $\left(175{ }^{\circ} \mathrm{C}<\mathrm{T}<2135^{\circ} \mathrm{C}\right)$, foram submetidas às análises físico-químicas no Laboratório THERMTEK-FEQ-UFPA, de acordo com os Métodos Oficiais AOCS e ASTM em termos do Índice de Acidez AOCS Cd 3d-63, Índice de Saponificação AOCS Cd 3-25, Densidade pelo método do Picnômetro ASTM D854 at $25^{\circ} \mathrm{C}$, Índice de Refração ajustando o Refratômetro Abbé com água destilada (IR $20^{\circ} \mathrm{C}=1.333$ ) AOCS Cc 7-25, Viscosidade Cinemática EN/ISO 3104, ASTM 446 e ASTM D 2515 usando um Viscosímetro Cannon-Fenske (Schot Geräte, Modelo: 520 23), com tubo capilar No. 200, Corrosividade ao Cobre ABNT/NBR 14359, usando o equipamento (PETROTEST DP, Modelo: E 25-0600), e Ponto de Fulgor ASTM D93, usando o equipamento Pensky-Martens Closed Cup (TANAKA, Modelo: APM7/FC-7).

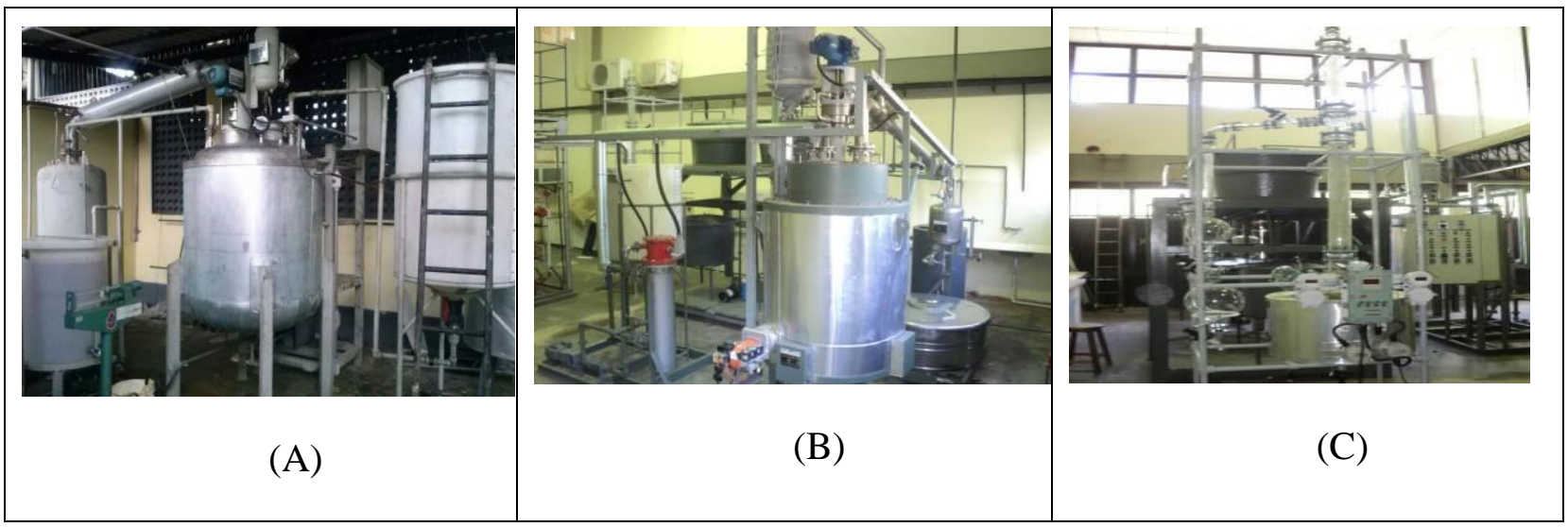

Figura 3 - Unidades Piloto de Desidratação (A), Craqueamento Termo-Catalítico (B), e Destilação (C) (THERMTEK-FEQ-UFPA).

\section{RESULTADOS E DISCUSSÃO}

\subsection{Balanço de Matéria}

Pré-processamento e craqueamento termo-catalítico: A Tabela 1 mostra os Balanços de Matéria e Rendimentos (Base Seca e Úmida) das Etapas de Pré-Processamento do Material Residual da Caixa de Gordura e Craqueamento Termo Catalítico da Gordura Líquida Homogeneizada. O rendimento 
( $)$ do Processo de Craqueamento Termo Catalítico em Base Úmida foi de $49.89 \%$ e em Base Seca $68.72 \%$.

Tabela 1 - Balanços de Matéria e Rendimentos das Etapas de Pré-Processamento do Material Residual da Caixa de Gordura e Craqueamento Termo Catalítico da Gordura Líquida.

\begin{tabular}{|l|l|l|l|l|}
\hline Pré-Processamento & Caixa de Gordura & Peneiramento & Decantação & Homogeneização \\
\hline & Material Residual & Sólidos & Fase Aquosa & Gordura Líquida \\
\hline $\mathrm{M}[\mathrm{kg}]$ & & & & 37 \\
\hline$\eta$ Base Úmida [\%] & & & & \\
\hline Craqueamento & Água & Coque & Gás & PLO \\
\hline $\mathrm{M}[\mathrm{kg}]$ & 10.14 & 4.35 & 4.05 & 18.46 \\
\hline$\eta$ Base Seca $[\%]$ & & 16.20 & 15.08 & 68.72 \\
\hline$\eta$ Base Úmida $[\%]$ & 27.40 & 11.76 & 10.95 & 49.89 \\
\hline
\end{tabular}

Destilação fracionada do produto líquido orgânico: A Tabela 2 ilustra os resultados da Destilação em Escala Piloto, na qual foram introduzidos $8.36 \mathrm{~kg}$ de PLO na Coluna de Destilação. Após as Etapas de Decantação e Filtração, obteve-se $1.26 \mathrm{~kg}$ de Querosene Verde e $7.01 \mathrm{~kg}$ de refinado.

Tabela 2 - Balanço de Matéria da Destilação em Escala Piloto do PLO.

\begin{tabular}{|c|c|c|c|}
\hline Destilação & \multicolumn{1}{|c|}{ PLO } & Destilado & Refinado \\
\hline $\mathrm{M}[\mathrm{kg}]$ & 8.36 & 1.26 & 8.1 \\
\hline
\end{tabular}

\subsection{Análises Físico-químicas e Bacteriológicas}

Análises físico-químicas e bacteriológicas da fase aquosa: Analisando os resultados da caracterização físico-química e bacteriológica das amostras 1 e 2, ilustrados na Tabela 3, pode-se observar que as variáveis $\mathrm{pH}, \mathrm{DBO5}, \mathrm{N}$-amoniacal e Coliformes Termotolerantes não se enquadram nos valores dos parâmetros estabelecidos pela Portaria No 357/2005 do CONAMA. 
Tabela 3 - Análises físico-químicas e bacteriológicas da Fase Aquosa.

\begin{tabular}{|c|c|c|}
\hline Parâmetros & Amostra 1 & Amostra 2 \\
\hline $\mathrm{Ph}$ & 5,6 & 6,9 \\
\hline$\overline{\mathrm{DQO}}\left[\mathrm{mg} \cdot \mathrm{L}^{-1}\right]$ & 3080 & 1620 \\
\hline $\mathrm{DBO}\left[\mathrm{mg} \cdot \mathrm{L}^{-1}\right]$ & 992 & 973 \\
\hline $\mathrm{N}$-Amoniacal $\left[\mathrm{mg} . \mathrm{L}^{-1}\right]$ & 91 & 114,5 \\
\hline SS $\left[\mathrm{mL} \cdot \mathrm{L}^{-1}\right]$ & 250 & 4 \\
\hline SST [mg.L $\left.L^{-1}\right]$ & 1060 & 3518 \\
\hline $\mathrm{SSF}\left[\mathrm{mg} \cdot \mathrm{L}^{-1}\right]$ & 60 & 22 \\
\hline SSV $\left[\mathrm{mg} \cdot \mathrm{L}^{-1}\right]$ & 1000 & 3497 \\
\hline ST $\left[\mathrm{mg} . \mathrm{L}^{-1}\right]$ & 78153 & 3398 \\
\hline STF $\left[\mathrm{mg} \cdot \mathrm{L}^{-1}\right]$ & 73939 & 874 \\
\hline STV $\left[\mathrm{mg} \cdot \mathrm{L}^{-1}\right]$ & 4214 & 2524 \\
\hline AT $\left[\mathrm{mg} . \mathrm{L}^{-1}\right]$ & 165 & 450 \\
\hline $\mathrm{AGV}\left[\mathrm{mg} \cdot \mathrm{L}^{-1}\right]$ & 125 & 365 \\
\hline Sulfato [mg.L $\left.\mathrm{L}^{-1}\right]$ & 350 & 100 \\
\hline Fósforo Total $\left[\mathrm{mg} \cdot \mathrm{L}^{-1}\right]$ & 75,5 & 81 \\
\hline Coliformes Totais [NMP.L $\left.{ }^{-1}\right]$ & $1011,2 \times 10^{4}$ & $913,9 \times 10^{4}$ \\
\hline Coliformes Termotolerantes & $755,6 \times 10^{4}$ & $629,4 \times 10^{4}$ \\
\hline
\end{tabular}

Análises físico-químicas da gordura residual, PLO e bioquerosene: A Tabela 4 apresenta os resultados da caracterização físico-química da Gordura Residual Líquida, PLO e Bioquerosene. Os resultados do PLO foram comparados com as especificações da resolução da ANP $N^{\circ} 65$ para diesel derivado do petróleo e os resultados do bioquerosene foram comparados com as especificações da resolução da ANP No 37 para querosene derivado do petróleo. Observa-se que o Índice de Acidez do PLO de $14.97 \mathrm{mg} \mathrm{KOH} / \mathrm{g}$, apresentou um valor considerado baixo quando comparado com os valores obtidos na literatura (SUAREZ et al. 2004). A densidade e o Ponto de Fulgor do PLO, estão de acordo com as especificações estabelecidas pela ANP $\mathrm{N}^{\circ}$ 65. Observou-se também uma redução significativa nos valores do Índice de Acidez, Índice de Saponificação e Viscosidade, após o craqueamento térmico catalítico da Gordura Residual Líquida.

Tabela 4 - Análises físico-químicas da Gordura Residual, PLO e Bioquerosene.

\begin{tabular}{|l|c|l|c|c|c|}
\hline \multicolumn{1}{|c|}{ Parâmetros } & Gordura Residual & PLO & ANP N $^{\circ}$ 65 & Bioquerosene & ANP N $^{\circ}$ 37 \\
\hline Densidade [g/cm ${ }^{3}$ ] & 0.98 & 0.82 & $0.82-0.85$ & 0.80 & - \\
\hline IA [mg KOH/g] & 72.73 & 14.97 & - & 4.75 & Máx 0,015 \\
\hline Índice de Refração [-] & - & 1.45 & - & 1.48 & - \\
\hline Ponto de Fulgor [ $\left.{ }^{\circ} \mathrm{C}\right]$ & - & 65 & $\geq 38$ & 42 & $\geq 38$ \\
\hline Viscosidade [cSt] & 9.4 & 1.19 & $2.0-4.5$ & - & 8 \\
\hline IS [mg KOH/g] & 120.19 & 22.93 & - & 7.46 & - \\
\hline Corrosividade $(1 \mathrm{~A})$ & 1 & 1 & 1 & 1 & 1 \\
\hline
\end{tabular}




\section{CONCLUSÃO}

Os resultados das propriedades físico-químicas das frações semelhantes ao Bioquerosene demonstram o Potencial do Processo de Craqueamento Térmico Catalítico do Material Residual de Caixas de Gordura, utilizando-se $10 \%(\mathrm{~m} / \mathrm{m})$ de $\mathrm{Na}_{2} \mathrm{CO}_{3}$ como catalisador, seguido da destilação do PLO, na Produção de Biocombustíveis.

\section{REFERÊNCIAS}

Agência Nacional do Petróleo, Gás Natural e Biocombustíveis, Resolução ANP $\mathrm{N}^{\circ}$ 37, DE 01.12.2009 - DOU 02.12.2009.

Agência Nacional do Petróleo, Gás Natural e Biocombustíveis, Resolução ANP $N^{\circ}$ 65, DE 09.12.2011 - DOU 12.12.2011.

BARROS, A.A.C., WUST, E., MEIER, H.F., Estudo da viabilidade de técnico-científica da produção de biodiesel a partir de resíduos gordurosos, Engenharia ambiental 2008; 13: 255 -262.

KNOTHE, G.; VAN GERPEN, J.; KRAHL, J.; RAMOS, L.P. Manual de Biodiesel. Ed. Edgard Blucher, São Paulo, SP, 2009.

LIMA, D.G., SOARES, V.C.D., RIBEIRO, E.B., CARVALHO, D.A., CARDOSO, E.C.V., RASSI, F.C., MUNDIM, K.C., RUBIM, J.C., SUAREZ, P.A.Z., Diesel-like fuel obtained by pyrolysis of vegetable oils, Journal of Analytical and Applied Pyrolysis 71 (2004) 987-996.

MARCHETTI, J. M.; MIGUEL, V. U.; ERRAZU, A. F. Pooible methods for biodiesel production. Renewable \&Sustainable Energy Reviews. v. 11, p. 731-736, 2005.

MEHER, L.C.;SAGAR, D. V.; NAIK, S. N. Technical aspects of biodiesel production by transesterification- A review. Renewable \& Sustainable Energy Reviews, v. 10, p. 248-268, 2006.

MOTA, S. A. P.; Craqueamento Termocatalítico de Óleos Vegetais em Diferentes Escalas de Produção. 2013. 332.f. Tese (Doutorado em Engenharia de Recursos Naturais da Amazônia) Universidade Federal do Pará. Belém/PA, 2013.

RATTON, A. R. Produção de Hidrocarbonetos a partir do Craqueamento de Resíduos provenientes de Caixa de Gordura. 2012. 107 f. Dissertação (Mestrado em Química) - IME, RJ, 2012.

Resolução CONAMA No 357 de 17 de Março de 2005. 